\title{
The effect of inbreeding, body size and morphology on health in dog breeds
}

\author{
Danika Bannasch ${ }^{1 *} \mathbb{D}$, Thomas Famula², Jonas Donner ${ }^{3}$, Heidi Anderson $^{3}$, Leena Honkanen ${ }^{3}$, Kevin Batcher $^{1}$, \\ Noa Safra ${ }^{1,4}$, Sara Thomasy, ${ }^{5,6}$ and Robert Rebhun ${ }^{5}$
}

\begin{abstract}
Background: Dog breeds are known for their distinctive body shape, size, coat color, head type and behaviors, features that are relatively similar across members of a breed. Unfortunately, dog breeds are also characterized by distinct predispositions to disease. We explored the relationships between inbreeding, morphology and health using genotype based inbreeding estimates, body weight and insurance data for morbidity.

Results: The average inbreeding based on genotype across 227 breeds was $F_{\text {adj }}=0.249$ ( $\left.95 \% \mathrm{Cl} 0.235-0.263\right)$. There were significant differences in morbidity between breeds with low and high inbreeding $(H=16.49, P=0.0004)$. There was also a significant difference in morbidity between brachycephalic breeds and non-brachycephalic breeds $(P=0.0048)$ and between functionally distinct groups of breeds $(H=14.95 P<0.0001)$. Morbidity was modeled using robust regression analysis and both body weight $(P<0.0001)$ and inbreeding $(P=0.013)$ were significant $\left(r^{2}=0.77\right)$. Smaller less inbred breeds were healthier than larger more inbred breeds.
\end{abstract}

Conclusions: In this study, body size and inbreeding along with deleterious morphologies contributed to increases in necessary health care in dogs.

Keywords: Canine, Genetic, Inherited, Morbidity, Mortality

\section{Background}

Most modern dog breeds were established within the last 200 years [1]. Dog breeds can be characterized by small numbers of founders, with strong selection for morphology, size and color. In addition, population bottlenecks due to historical events, and the introduction of closed studbooks in the last 100 years has shaped the formation of modern dog breeds [2]. These factors have all contributed to high levels of inbreeding within breeds. The level of inbreeding can be estimated using pedigrees, which were commonly used to determine the coefficient of inbreeding $\left(\mathrm{F}_{p}\right)$ within individuals and breeds [3];

\footnotetext{
*Correspondence: dlbannasch@ucdavis.edu

${ }^{1}$ Department of Population Health and Reproduction, School

of Veterinary Medicine, University of California-Davis, Davis, CA 95616, USA

Full list of author information is available at the end of the article
}

however, unless calculations include the complete pedigree $[4,5], \mathrm{F}_{p}$ may underrepresent the actual inbreeding by $5-10$ fold [6-8]. More recently, measurement of genetic inbreeding levels through direct genotype-based methods has become a feasible option. Such approaches to determine inbreeding have provided evidence that dog breeds $[4,5,8,9]$ have levels of inbreeding that are considered extremely high $(>0.1)$ in other species and where the effects of inbreeding depression are expected to occur [10-12].

There is evidence that high levels of inbreeding have consequences on health. Close inbreeding has a negative effect on litter size and neonatal survival [13]. Domestication and breed formation have unintentionally increased the number of deleterious genetic variants within breeds $[14,15]$. Individual breeds also have strong predispositions to specific inherited diseases [16-19]. The Online Mendelian Inheritance in Animals website original author(s) and the source, provide a link to the Creative Commons licence, and indicate if changes were made. The images or other third party material in this article are included in the article's Creative Commons licence, unless indicated otherwise in a credit line to the material. If material is not included in the article's Creative Commons licence and your intended use is not permitted by statutory regulation or exceeds the permitted use, you will need to obtain permission directly from the copyright holder. To view a copy of this licence, visit http://creativecommons.org/licenses/by/4.0/. The Creative Commons Public Domain Dedication waiver (http://creativeco mmons.org/publicdomain/zero/1.0/) applies to the data made available in this article, unless otherwise stated in a credit line to the data. 
(OMIA, April 2021, omia.org) currently catalogues 796 canine disorders and traits [20]. Some of these have been found to be due to high allele frequencies of deleterious recessive mutations (for example [21, 22]), while others have remained elusive and are likely polygenic in nature $[23,24]$. Some of the breed disease predispositions may be due to concentrated genetic disease polymorphisms rather than segregating traits $[25,26]$. Consistent with this theory, mixed breeds have lower risk of diseases than purebreds [27]; however, the risk can vary by disease [28, 29 ] and has not been evaluated by level of inbreeding.

Body size and morphology vary within and between breeds and have an effect on lifespan in dogs. Breed average lifespan is inversely correlated with breed average body weight [30], with smaller dogs living longer than larger dogs. However, lifespan differs between breeds of the same weight class indicating that more than body size is a factor [31-33]. Morphological characteristics of dog breeds could be one factor, since it can have a critical effect on their lifespan and health [18, 34]. Results for the effect of inbreeding on mortality have varied between previous studies [9, 32].

Overall health comparisons across breeds have been challenging to perform since individual measurements are not available. In addition to the examples cited in the previous paragraph, there are numerous examples in the canine literature of the utilization of breed average measures for height, weight and health for successful genetic association studies [35-43]. In some examples, breedaverage measures resulted in a clear increase in GWAS power for detecting body size associations (compared to individual phenotypes) [40].

We utilize complied pet insurance data reported relative to number of years insured to quantify relative health across dog breeds. Breed-based morbidity measures (non-routine veterinary care events) were compared to breed morphology, body size and estimates of inbreeding based on genotypes. High levels of inbreeding were identified across breeds as expected. Robust regression analysis identified statistically significant effects of both inbreeding and body size on morbidity across breeds.

\section{Results}

A large dataset (227 breeds; dataset 1) of median heterozygosity values $(\mathrm{H})$ was obtained through commercial DNA testing of 49,378 dogs. The mean number of individuals per breed was 217.5 (95\% Confidence Interval 162-273.1) and the range of individual dogs/breed was $30-4728$. Since the $H$ values do not provide a simple relationship to pedigree, we wanted to determine what their equivalency was to the coefficient of inbreeding (F). The genotype-based coefficient of inbreeding was determined in 19 breeds with $8-20$ individuals in each breed (dataset 2) for comparison to dataset 1. Dreger at al [8] used 10 individuals per breed and calculated F based on genotypes and the correlation with dataset 2 was 0.85 (12 breeds in common). Yordy et al. [9] used 6-724 individuals per breed and the correlation with dataset 2 was 0.75 (15 breeds in common). $\mathrm{F}$ from dataset 2 was highly correlated with $\mathrm{H}$ from dataset 1 (Pearson correlation coefficient of $-0.8899(P<0.0001)$ for the same 19 breeds. Linear regression $\left(r^{2}=0.79\right)$ was performed to obtain adjusted $F$ values $\left(F_{\text {adj }}\right)$ for the dataset 1 breeds. Based upon linear regression, an $\mathrm{H}$ value of $33.1 \%$ was equivalent to $\mathrm{F}$ of 0.25 . The $\mathrm{H}$ values were adjusted based on the regression to provide breed estimates of inbreeding for the 227 breeds in dataset $1\left(\mathrm{~F}_{\mathrm{adj}}\right)$. These adjusted values from dataset 1 were compared to adjusted values from [9] which included 97 breeds in common and the Pearson correlation was 0.883 and [8] which included 75 breeds in common and was 0.89 .

The mean of the $\mathrm{F}_{\text {adj }}$ values for 227 breeds was 0.249 (95\% CI 0.235-0.263) (Fig. 1). Strikingly few breeds $(N=12)$ had low inbreeding values $(<0.10)$. The breeds with the lowest levels of inbreeding were mostly landrace breeds or breeds with recent cross breeding. To put the

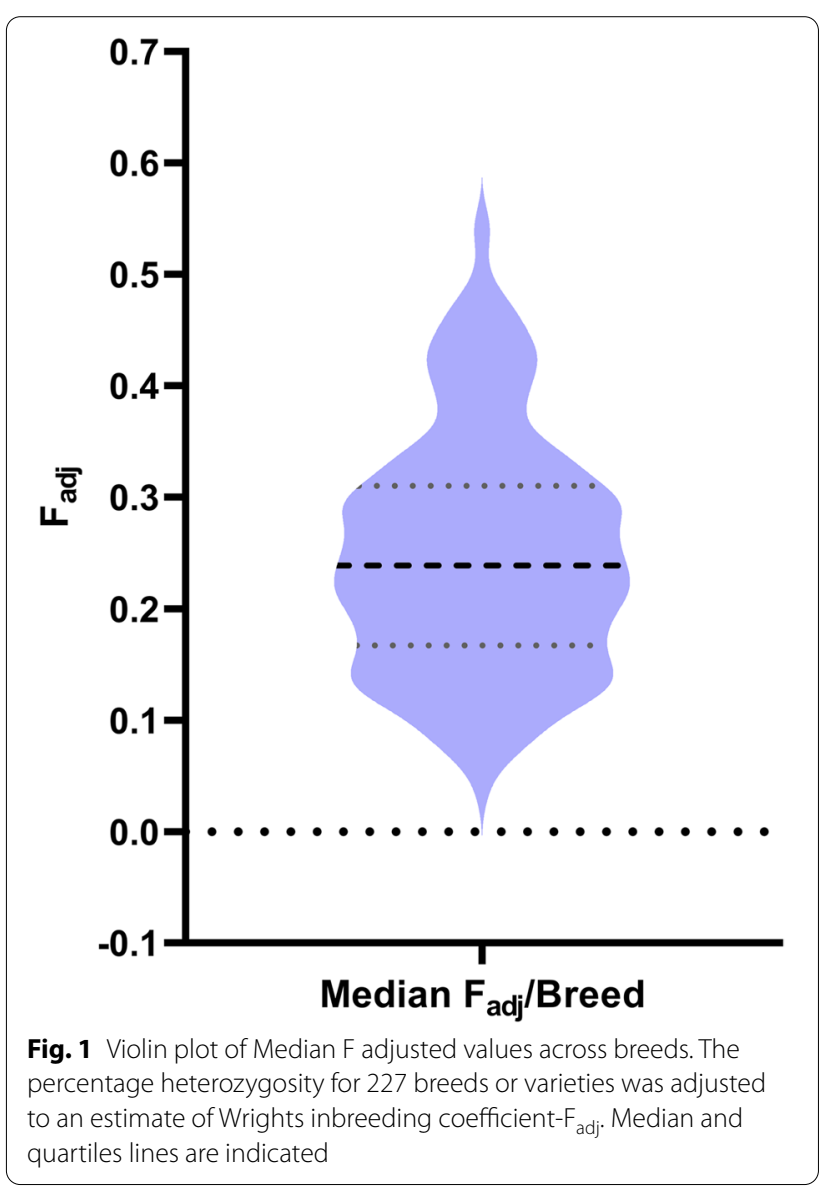


inbreeding values in context, the breeding of two first cousins produces $\mathrm{F}=0.0625$, two half siblings $\mathrm{F}=0.125$ and two full siblings or parent-offspring $\mathrm{F}=0.25$.

In order to investigate the effect of inbreeding level on health we utilized breed-based health data from Agria pet insurance. Morbidity values were available for 162 of the breeds with $\mathrm{F}_{\mathrm{adj}}$ values. The mean morbidity across all breeds was 1574 (95\% CI 1527-1622) per 10,000 DYAR (Dog Year at Risk) and for mixed breeds it was 1265. Morbidity was compared between three different categories of inbreeding (Fig. 2).

Breeds were evaluated based on their FCI (Fédération Cynologique Internationale) groups as a means of uncovering differences in health and inbreeding between breed types. There was no significant difference between FCI groups for inbreeding $\mathrm{F}_{\text {adj }}(P=0.06)$, however there were significant differences between groups for morbidity (Kruskal-Wallis, $P<0.0001$ ) (Fig. 3). Most notably, FCI group 5 composed of primitive breeds had low mean morbidity (1308) and group 2 which includes the Molossian/Mastiff types had a very high mean morbidity (1897) (a $45 \%$ increase). It should be noted that both body size and morphology can vary within most of these groups.

Breed morphology was evaluated using the Mann Whitney $U$ test to determine if there were differences in morbidity between morphological breed groupings. Brachycephalic breeds had significantly higher morbidity and median inbreeding than non-brachycephalic breeds, but lower median body weight (Table 1).

In order to evaluate the effects of body weight and inbreeding on morbidity in dogs, Spearman correlations were performed. Spearman $\mathrm{r}$ between morbidity and $\mathrm{F}_{\text {adj }}$ was $0.29, P=0.0002$ and between morbidity and body weight it was $0.41, p<0.0001$. Recognizing that there was a complex relationship we developed a model to predict morbidity across breeds which included body weight and median inbreeding. Brachycephalic breeds were excluded since their conformation so heavily influenced their health leaving 148 breeds with morbidity, inbreeding and body size data.

Parameter estimates for the robust regression analysis are shown in Table 2. The most striking element of the table is the significant difference that both $\mathrm{F}_{\mathrm{adj}}$ and body weight appear to exert on morbidity across breeds. The $r^{2}$ for this model is 0.77 . In order to put these results in context, we have graphed morbidity versus body weight and added regression lines for the effect of different inbreeding levels (Fig. 4).

\section{Discussion}

Breed average measures of inbreeding, body weight and cumulative insurance data on morbidity were used to identify a relationship between body size, body

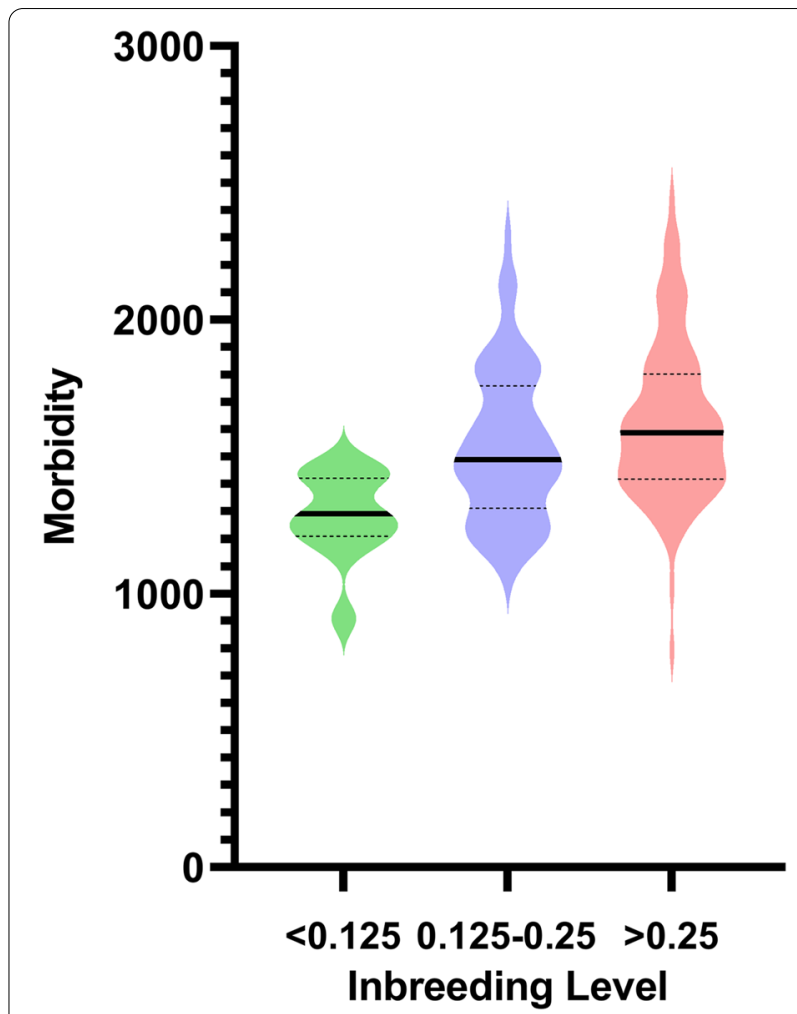

Fig. 2 Morbidity by inbreeding levels. Morbidity values as VCE/10,000 dog years at risk ( $95 \%$ confidence intervals and mean are shown) plotted by mean $\mathrm{F}_{\text {adj }}$ within each breed in relevant categories. There were 11 breeds with $F_{\text {adj }}<0.125$; mean morbidity for those breeds was $1282(95 \% \mathrm{Cl} 1173-1391)$. For $F_{\text {adj }}$ between 0.125 and 0.25 , there were 66 breeds with a mean of 1537 (95\% Cl 1468-1606), and for $F_{\text {adj }}$ over 0.25 there were 85 breeds with a mean of 1626 (95\% Cl 1562-1690). Significant differences for morbidity were identified between the three categories of $F_{\text {adj }}$ using Kruskal-Wallis test $(P=0.0003)$. The relative risk morbidity compared to mixed breed dogs ( $F=0$ in dataset 1 and $F_{a d j}=0.037$ in dataset 2) for low inbred dogs was 1.01 , meaning that they have a $1 \%$ increase in veterinary care events compared to mixed breed dogs. Breeds with inbreeding between 0.126 and 0.25 had a relative risk of 1.22 i.e. a $22 \%$ increase in veterinary care events while breeds with inbreeding over 0.25 had a relative risk of 1.29 i.e. a $29 \%$ increase in veterinary care events compared to mixed breed dogs

morphology, inbreeding and health in dogs. Breeds with higher inbreeding levels required greater amounts of veterinary care as did brachycephalic breeds and there were significant differences in required health care between FCI breed groupings. We identified a significant effect of both body size and inbreeding on morbidity across dog breeds with larger sized and more inbred breeds receiving more veterinary care throughout their lives.

The inbreeding values within dog breeds were very high, with the mean being 0.24 , just below the coefficient of inbreeding obtained from breeding full siblings. The breeds with low inbreeding included recent 


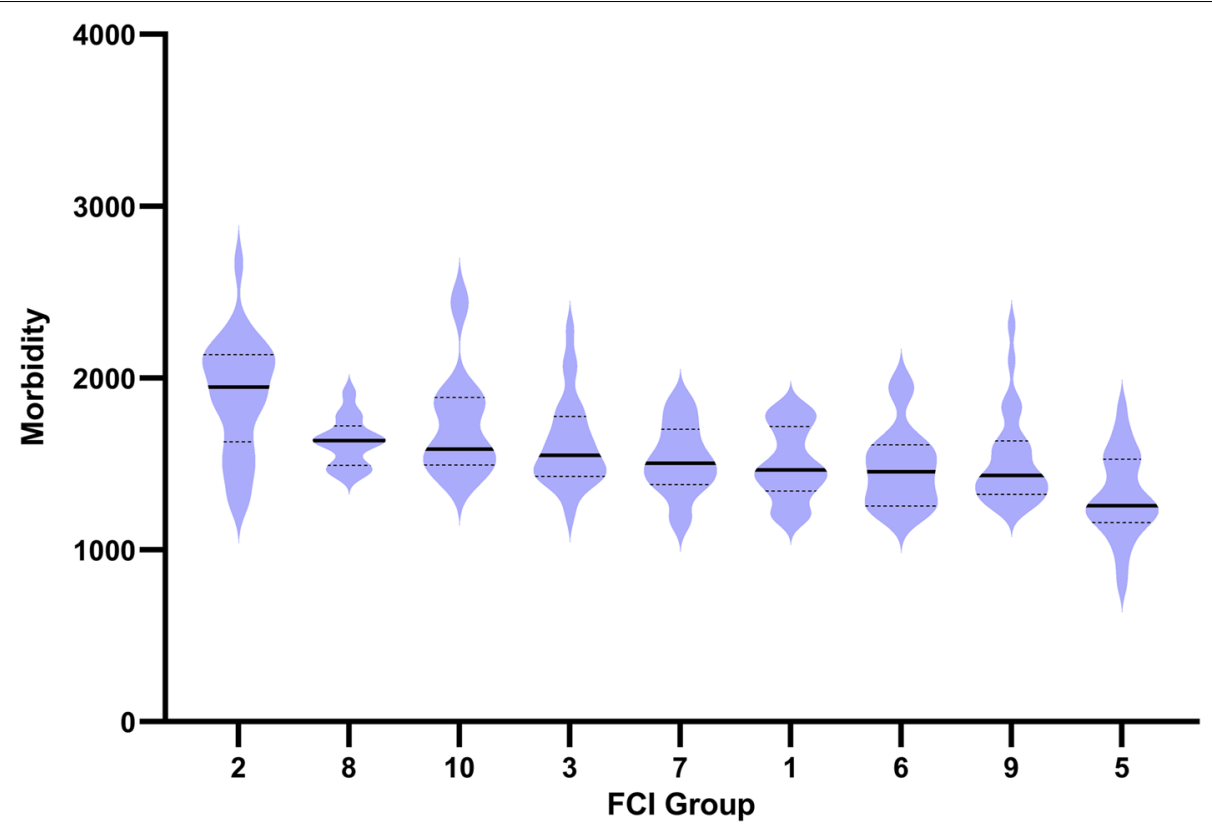

Fig. 3 Morbidity values within $\mathrm{FCl}$ groups. Violin plots of morbidity as number of veterinary care events/10,000 dog years at risk plotted by $\mathrm{FCl}$ group (95\% Confidence intervals and mean are shown). $\mathrm{FCl}$ breed groupings are ordered from high mean morbidity on the left to low mean morbidity on the right. $2=$ pinscher, schnauzer, molossoid, swiss mountain and cattle dogs, $8=$ retrievers, $10=$ sighthounds, $3=$ terriers, $7=$ pointing dogs, $1=$ sheepdogs and cattledogs, $6=$ scent hounds and dachshunds, $9=$ companion and toy, and $5=$ spitz and primitive types

Table 1 Comparison of Brachycepahlic and non-brachycephalic breeds

\begin{tabular}{|c|c|c|c|}
\hline & Non-Brachycephalic & Brachycephalic & $P$ value \\
\hline $\begin{array}{l}\text { Morbidity } \\
\text { Median/10000 } \\
\text { DYAR }\end{array}$ & $1508(N=148)$ & $1829(N=14)$ & 0.0048 \\
\hline $\mathrm{F}_{\mathrm{adj}}$ & 0.2450 & 0.319 & 0.0025 \\
\hline Body weight & 18.26 & 6.69 & 0.0262 \\
\hline
\end{tabular}

Table 2 Parameter estimates for the analysis of morbidity in a model with regressions on body weight and inbreeding

\begin{tabular}{llll}
\hline Parameter & Estimate & Std Error & $P$ value \\
\hline Intercept & 1618.6 & 115.48 & $<0.0001$ \\
Fadj $_{\text {(10\%) }}$ & 38.69 & 3.2 & 0.013 \\
Body Weight $(1 \mathrm{~kg})$ & 9.36 & 1.07 & $<0.0001$ \\
\hline
\end{tabular}

cross breeds (Tamaskan Dog, Barbet and Australian Labradoodle) and landrace breeds (Danish-Swedish Farmdog, Mudi and Koolie), supporting the notion that high inbreeding is a result of closed stud books or small numbers of founders or both. It also demonstrates that it is possible to have consistent breed type without inbreeding.
Similar to another recent study, brachycephalic dogs require more veterinary care than non- brachycephalic dogs [34]. In addition, we identified that FCI group 2 breeds required the highest average number of veterinary care events. This group includes the larger molossoid dog breeds which others have previously identified as having higher mortality $[32,44]$. The primitive FCI group 5 breeds had the lowest average morbidity of all the groups, which has not been reported previously, except for the Norrbottenspitz breed [45]. This may be, in part, due to the large number of primitive breeds for which there is insurance data available in our data set, while other studies may not have had health data available for these breeds.

There were interesting exceptions to the correlation of inbreeding and health. The Border terrier, Basenji, Collie, and English setter breeds have high inbreeding but low morbidity. Likewise, the Malinois, Pomeranian and Russian Tsvetnaya Bolonka (Russian Toy) have lower inbreeding and high morbidity. These example breeds are neither brachycephalic nor particularly known for extreme morphologies. In the case of healthy breeds with high inbreeding, it may be possible that these breeds have been purged of deleterious alleles as has happened with inbred mouse strains [46]. In the opposite situation (lower inbreeding and high morbidity), the recorded morbidities could be high allele frequency Mendelian 


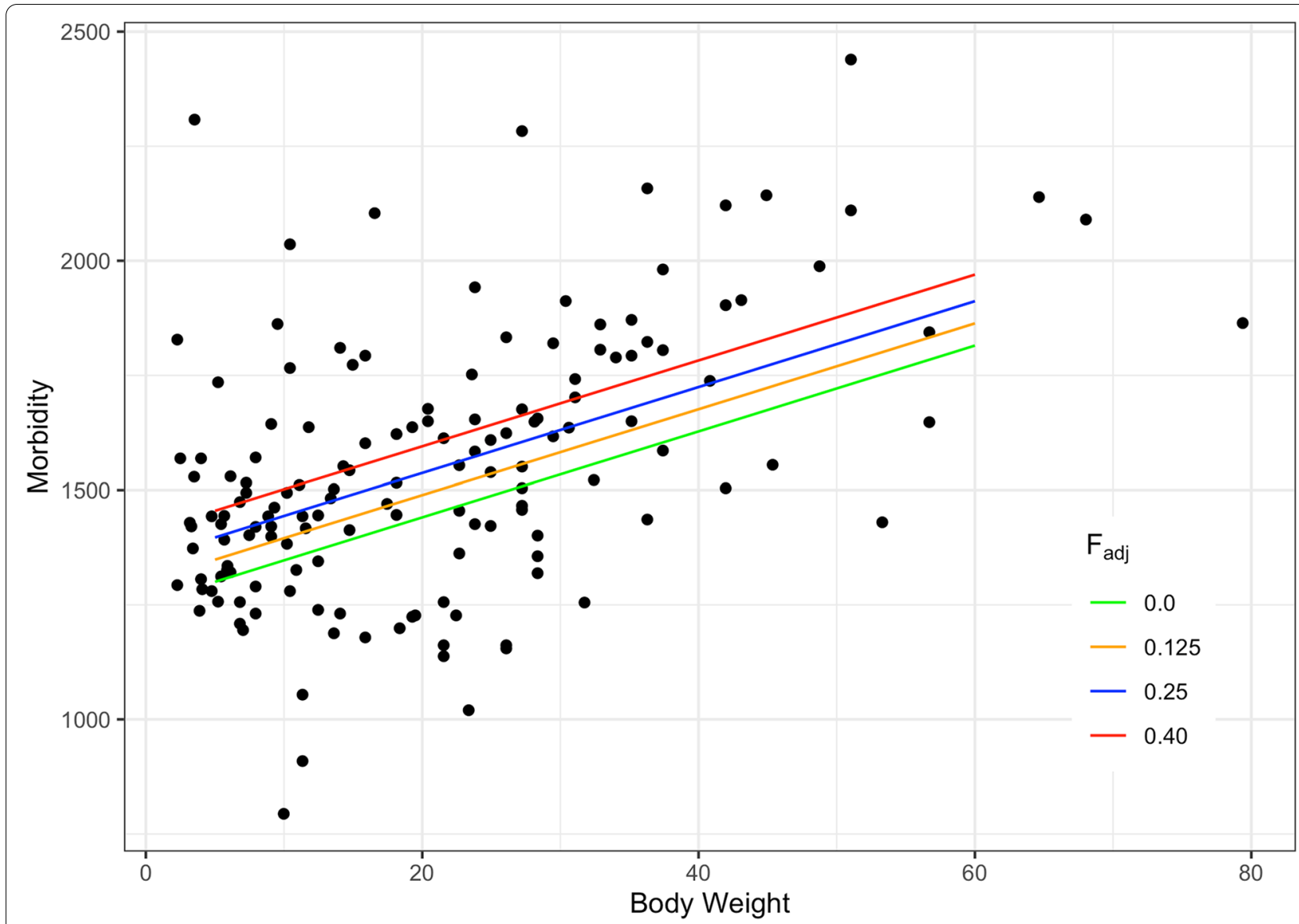

Fig. 4 Morbidity as a function of body weight and inbreeding. Morbidity in number of veterinary care events /10,000 dog years at risk for breeds plotted by mid-range body weight. Regression lines are shown for different levels of inbreeding as indicated. As an example, the morbidity values for a $30 \mathrm{~kg}$ dog at no inbreeding $\left(F_{\text {adj }}=0\right)$ are predicted to be 1534.5 (SE 36.75) compared to high inbreeding $\left(F_{\text {adj }}=0.40\right) 1688$ (SE 24.47$)$ which is a $10 \%$ increase in veterinary care events. The morbidity value for a $5 \mathrm{~kg}$ dog at $F=0.25$ is 1396.9 (SE 18.88) and for a $60 \mathrm{~kg}$ dog it is 1911.8 (SE 38.67 ), which is a $37 \%$ increase in veterinary care events

diseases or potentially conditions linked to phenotypes under selection in the breed. These discrepancies could also exist due to population differences between the insurance data and the inbreeding data.

A caveat for this analysis is the utilization of breed average values rather than specific measurements on individual animals for body weight, inbreeding and health. The utilization of breed average values could lead to over or under estimates of the effects of inbreeding on health. As veterinary health databases become more developed and DNA testing more widespread this type of data would be extremely useful across large numbers of individual dogs. None the less, inbreeding values from this work were comparable to levels obtained by other researchers using different methodologies and different populations of dogs $[8,9,47,48]$.

A demonstration of direct negative effects of inbreeding within breeds has been limited, likely due to the need to use molecular tools to determine actual historic inbreeding, the absence of dogs with low inbreeding $(<0.1)$ or no inbreeding and the challenges of phenotyping for individual animals. Inbreeding (range $0.2-0.48$ ) based on runs of homozygosity was associated with smaller litters in Golden retrievers [49]. Inbreeding in dams (0.32-0.45) was associated with fertility in the Entlebucher Mountain $\operatorname{dog}$ [50]. One challenge for the associations performed within breeds is the overall high level of inbreeding within the breeds which does not allow the full range of inbreeding levels to be evaluated relative to health traits. In this study we took advantage of the availability of insurance data to evaluate morbidity. It is estimated that $40 \%$ of dogs in Sweden are insured, allowing the insurance data to provide a good estimate of the population as a whole [51], and the ability to use dogs years at risk in the denominator allows comparisons across breeds and factors in length of insurance coverage $[31,52]$. One challenge with 
comparing across breeds is that insurance coverage is ended for breeds at different ages and the average age of insured dogs differs between breeds.

The heterozygosity values were obtained from worldwide sample collection centered in the Scandinavian countries. Dataset 2 was from samples collected predominantly in the United States and there was strong correlation with the heterozygosity values. Other groups have also identified strong correlation between heterozygosity values and inbreeding based on commercial testing in the United States [9]. The insurance data is mostly from Sweden, however Agria Pet Insurance does operate in other countries as well. There is some evidence of population stratification between countries for different breeds and types of dogs, however the effect on overall levels of inbreeding was not high [53].

The results for the effects of inbreeding on mortality have been varied between studies with some finding a significant effect [32] and others not [9]. One reason that previous results were inconsistent with respect to the effects of inbreeding on mortality may be the consistently high levels of inbreeding that exist across the majority of purebred dog breeds such that there was not enough variation in the levels of inbreeding to detect an effect.

One must consider that the majority of dog breeds displayed high levels of inbreeding well above what would be considered safe for either humans or wild animal populations. The effects of inbreeding on overall fitness have been demonstrated experimentally using mice, where an overall reduction in fitness between mice with $\mathrm{F}=0.25$ compared to $\mathrm{F}=0$ was determined to be $57 \%$ [54]. While this high level of inbreeding was less relevant to many captive and wild species, it is highly relevant to purebred dogs, based on the average inbreeding identified in this study. However the rate of inbreeding between these mouse experiments and what has occurred in dogs breeds is not the same and could have an effect on health. In humans, modest levels of inbreeding (3-6\%) were shown to be associated with increased prevalence of late onset complex diseases [55] as well as other types of inbreeding depression [11]. These findings in other species combined with the incredibly strong breed predispositions to complex diseases like cancers and autoimmune diseases highlight the potential relevance of high inbreeding in dogs to their health.

\section{Conclusions}

Additional studies to evaluate the effects of inbreeding on health need to be performed on an individual animal basis and should include the entire scale of inbreeding levels. Careful management of breeding populations to avoid additional loss of existing genetic diversity, through breeder education and monitoring of inbreeding levels enabled by direct genotyping technologies, is essential.
Outcrosses are being proposed for some breeds and conditions $[56,57]$ or have already been carried out as a measure to increase genetic diversity. Care must be taken to consider if these will effectively increase overall breed diversity and therefore reduce inbreeding [58]. In particular, in the few breeds with low inbreeding levels, every effort should be made to maintain the genetic diversity that is present. While history has shown how easily it can be lost in closed breed populations, encouragement can be found in breeds exemplifying a consistent and truebreeding type without high inbreeding levels.

\section{Methods \\ Samples}

Dataset 1 (Additional file 1). Median SNP heterozygosity values were obtained for 227 breeds or varieties based on 30-2520 individuals per breed (Total Count $=49,378$ ) using a genetic diversity screening test commercially available as MyDogDNA ${ }^{\mathrm{TM}}$ or Optimal Selection ${ }^{\mathrm{TM}}$ (Wisdom Health, Vancouver, WA, USA). This dataset consisted of non-invasive cheek swab samples collected by dog owners, and either blood or cheek swab samples collected at certified veterinary clinics, for submission to commercial DNA testing. The samples were submitted for MyDogDNA ${ }^{\mathrm{TM}}$ / Optimal Selection $^{\text {TM }}$ analysis between April 3rd, 2015 and June 23th, 2020. The breed of a dog was reported by its owner, typically with additional accompanying information confirming registration under Fédération Cynologique Internationale (FCI), American Kennel Club (AKC), United Kennel Club (UKC), or the Kennel Club (UK)

Dataset 2 (Additional file 2). DNA samples from 274 dogs (19 breed groups) were collected as controls for disease studies (Additional file 2). Dogs were selected that were unrelated to the second generation based on pedigree where available. Eight to twenty individuals per breed were used to determine F (see below). Fifty-nine dogs designated by their owners as mixes were also used in two groups: 33 were used to establish a SNP list for analysis (see F below) and the remaining 26 were used in the analysis as mixed breed samples

\section{Agria insurance data}

Agria Insurance data in the form of breed profiles were accessed from the International Partnership for Dogs (dogwellnet.com) and the data abstracted for use in this study. Agria insurance morbidity in veterinary care events/10,000 dog years at risk (DYAR) from 2011 to 2016 account for the actual time the dog was insured. Individuals were assessed only once for each category/diagnosis for $>=1$ veterinary care event (VCE). Morbidity values are the number of dogs experiencing VCE within each category/diagnosis that were not for preventive medicine or prophylactic measures since these are not covered by the 
policy. Agria insurance data was available for 162 breeds and mixes with some breed varieties combined differently from the Heterozygosity values of dataset 1 (Additional file 1).

Categorization as brachycephalic was determined for each breed based on breed standards as shown in Additional file 1. Group designations were based on the FCI group divisions with the exception of the dachshunds which were grouped as hounds in FCI group 6. Mid-range body weight for all breeds was obtained from the low female and high male weights if there were sex differences or between the low and high weight if there were no sex differences listed (www.akc.org).

\section{Inbreeding coefficient (F)}

All dogs from Dataset 2 were genotyped on the Illumina canine HD genotyping array (173K SNPs). Plink [59] was used to prune SNPs in 33 mixed breed dogs to identify SNPs in linkage equilibrium using the following parameters: --indep-pairwise 200, 50, 0.6, <window size $200 \mathrm{~kb}<$ step size [50] $><r^{2} 0.6$. This resulted in 96,497 autosomal markers. $\mathrm{F}$ as reported in this manuscript was calculated using the "ibc" function and FHAT 2 as implemented in plink which is based on the program GCTA (<observed hom. Count $>-<$ expected count $>) /(<$ total observations $>-<$ expected count $>$ ).

\section{Adjusted inbreeding coefficient $\left(F_{\text {adj }}\right)$}

$\mathrm{F}$ from dataset 2 was highly correlated with $\mathrm{H}$ from dataset 1 (Pearson correlation coefficient of -0.8899 $(P<0.0001)$ for the same 19 breeds. Linear regression was performed to obtain adjusted $\mathrm{F}$ values for each breed $\left(\mathrm{Y}=-0.02103^{*} \mathrm{X}+0.9456, r^{2}=0.79\right)$. The $\mathrm{H}$ values were adjusted based on the regression to provide breed estimates of inbreeding for 227 breeds $\left(\mathrm{F}_{\mathrm{adj}}\right)$.

\section{Statistics}

Pearson Correlation, descriptive statistics, Mann Whitney $U$ test, Kruskal-Wallis and linear regression as indicated were performed in GraphPad Prism (V. 9.0.1). Spearman correlation was performed for correlation of Morbidity and $\mathrm{F}_{\mathrm{adj}}$ and Morbidity and Body size since they were not normally distributed.

\section{Multiple regression analysis}

Modelling the morbidity scores as a function of the breed body weight and mean breed $\mathrm{F}_{\text {adj }}$ considers this simple linear model:

$$
y_{i}=b_{0}+b_{w} \text { Weight }_{i}+b_{f} F_{i}+e_{i}
$$

where $y_{i}$ is the observed morbidity score for the $i$-th breed, $b_{0}$ is an unknown constant common to all breeds, $b_{w}$ is the regression coefficient of mid-range body weight of the $i$-th breed (measured as Weight $t_{i}$ ) on morbidity, $b_{f}$ is the regression coefficient for average adjusted $\mathrm{F}$ of the $i$-th breed (measured as $F_{i}$ on a scale from 0 to 1.0) on morbidity, and $e_{i}$ is the unobserved residual error for the $i$-th breed. We consider the residual term for the $i$ th breed (i.e., $e_{i}$ ) to have null mean and variance $\sigma_{e}^{2} / n_{i}$, where $n_{i}$ is the sample size for the $i$-th breed.

An additional, and necessary, prerequisite of this analysis is the recognition that the variation in breed morbidity changes with breed body weight, there being more variability "in the tails" of this distribution than nearer the median. This form of heteroscedasticity can be better accommodated through the application of robust regression models [60]. Accordingly, model [1], was evaluated in the MASS package [61] of the public domain statistical language $R$ [62] . Tests of hypotheses regarding estimates of model parameters were facilitated through the package sfsmisc [63]. $r^{2}$ was computed (the 0.77 value) recognizing the fact that data points were weighted by sample size.

\section{Supplementary Information}

The online version contains supplementary material available at https://doi. org/10.1186/s40575-021-00111-4.

Additional file 1: Dataset 1. Table of breeds, numbers of individuals, heterozygosity values, $F_{\text {adj }}$ values, morbidity, group and morphology classifications

Additional file 2: Dataset 2. Breeds used for linear regression. Numbers of individuals, median, minimum and maximum inbreeding and median, minimum and maximum heterozygosity values are included.

\section{Acknowledgements}

We gratefully acknowledge the dog owners who have provided samples for research, Wisdom Health Genetics for sharing their data and Agria Insurance Sweden for producing Agria dog breed profiles. We appreciate constructive comments provided by Brenda Bonnett.

\section{Authors' contributions}

DB performed data analysis, wrote the manuscript, TF performed robust regression analysis and wrote portions of the manuscript, JD provided raw data and wrote portions of the manuscript, HA, LH, KB, NS, ST, and RR provided data. All authors read and edited the manuscript. The authors read and approved the final manuscript.

\section{Funding}

This work was supported by the International Canine Health Award and the Maxine Adler Endowed Chair Fund.

\section{Availability of data and materials}

All data generated or analyzed during this study are included in this published article and its additional files. 


\section{Declarations}

\section{Ethics approval and consent to participate}

DNA samples for Dataset 1 were collected in accordance with internationa standards for animal care and research as a part of voluntary submission of samples to commercial DNA testing. In addition, the dog owners provided consent for the use of their dog's DNA information for research purposes. DNA samples for Dataset 2 were collected under the supervision of the UC Davis Institutional Animal Care and Use Committee (protocol \#s 15356, 16895, and 18561).

\section{Consent for publication}

Not applicable.

\section{Competing interests}

$\mathrm{LH}, \mathrm{HA}$ and JD are employees of Wisdom Health that offers canine DNA testing as a commercial service.

\section{Author details}

'Department of Population Health and Reproduction, School of Veterinary Medicine, University of California-Davis, Davis, CA 95616, USA. ${ }^{2}$ Department of Animal Science, University of California-Davis, Davis, CA 95616, USA. ${ }^{3}$ Wisdom Health Genetics, Kinship, FI-00290 Helsinki, Finland. ${ }^{4}$ Zoetis, Parsippany, NJ, USA. ${ }^{5}$ Department of Surgical and Radiological Sciences, School of Veterinary Medicine, University of California-Davis, Davis, CA 95616, USA. ${ }^{6}$ Department of Ophthalmology \& Vision Science, School of Medicine, University of California-Davis, Davis, CA 95616, USA.

Received: 24 August 2021 Accepted: 2 November 2021

Published online: 02 December 2021

\section{References}

1. Morris D. Dogs: the ultimate dictionary for over 1,000 dog breeds. North Pomfret: Trafalgar Square Publishing; 2002.

2. Wayne RK, Ostrander EA. Lessons learned from the dog genome. Trends Genet. 2007;23(11):557-67.

3. Leroy G. Genetic diversity, inbreeding and breeding practices in dogs: results from pedigree analyses. Vet J. 2011;189(2):177-82.

4. Mäki K. Population structure and genetic diversity of worldwide Nova Scotia duck tolling retriever and Lancashire heeler dog populations. J Anim Breed Genet. 2010:127(4):318-26.

5. Letko A, Minor KM, Jagannathan V, Seefried FR, Mickelson JR, Oliehoek $P$, et al. Genomic diversity and population structure of the Leonberger dog breed. Genet Sel Evol. 2020;52(1):61.

6. Kardos M, Luikart G, Allendorf FW. Measuring individual inbreeding in the age of genomics: marker-based measures are better than pedigrees. Heredity (Edinb). 2015;115(1):63-72.

7. Kardos M, Taylor HR, Ellegren H, Luikart G, Allendorf FW. Genomics advances the study of inbreeding depression in the wild. Evol Appl. 2016;9(10):1205-18.

8. Dreger DL, Rimbault M, Davis BW, Bhatnagar A, Parker HG, Ostrander EA. Whole-genome sequence, SNP chips and pedigree structure: building demographic profiles in domestic dog breeds to optimize genetic-trait mapping. Dis Model Mech. 2016;9(12):1445-60.

9. Yordy J, Kraus C, Hayward JJ, White ME, Shannon LM, Creevy KE, et al. Body size, inbreeding, and lifespan in domestic dogs. Conserv Genet. 2020;21(1):137-48.

10. Baes CF, Makanjuola BO, Miglior F, Marras G, Howard JT, Fleming A, et al. Symposium review: the genomic architecture of inbreeding: how homozygosity affects health and performance. J Dairy Sci. 2019;102(3):2807-17

11. Yengo L, Wray NR, Visscher PM. Extreme inbreeding in a European ancestry sample from the contemporary UK population. Nat Commun. 2019;10(1):3719.

12. Hohenlohe PA, Funk WC, Rajora OP. Population genomics for wildlife conservation and management. Mol Ecol. 2021;30(1):62-82.

13. Leroy $G$, Phocas F, Hedan B, Verrier E, Rognon X. Inbreeding impact on litter size and survival in selected canine breeds. Vet J. 2015:203(1):74-8.
14. Marsden CD, Ortega-Del Vecchyo D, O'Brien DP, Taylor JF, Ramirez O, Vilà $C$, et al. Bottlenecks and selective sweeps during domestication have increased deleterious genetic variation in dogs. Proc Natl Acad Sci U S A. 2016;113(1):152-7.

15. Jagannathan $\mathrm{V}$, Drogemuller C, Leeb T. Dog biomedical variant database $C$. a comprehensive biomedical variant catalogue based on whole genome sequences of 582 dogs and eight wolves. Anim Genet. 2019;50(6):695-704

16. Gough A, Thomas A, O'Neill D. Breed predispositions to disease in dogs and cats, third edition. Breed predispositions to disease in dogs and cats. third ed. Hoboken: Wiley; 2018. p. 17-224.

17. Online Mendelian Inheritance in Animals, OMIA [Internet]. Sydney School of Veterinary Science. Available from: https://omia.org/.

18. Asher L, Diesel G, Summers JF, McGreevy PD, Collins LM. Inherited defects in pedigree dogs. Part 1: disorders related to breed standards. Vet J. 2009:182(3):402-11.

19. Summers JF, Diesel G, Asher L, McGreevy PD, Collins LM. Inherited defects in pedigree dogs. Part 2: disorders that are not related to breed standards. Vet J. 2010;183(1):39-45

20. Frank WN, Alice C, David RS. Internet resources cataloguing inherited disorders in dogs. Vet J. 2011;189(2):132-5.

21. Forman OP, Boursnell ME, Dunmore BJ, Stendall N, van den Sluis B, Fretwell $\mathrm{N}$, et al. Characterization of the COMMD1 (MURR1) mutation causing copper toxicosis in Bedlington terriers. Anim Genet. 2005;36(6):497-501.

22. Bannasch D, Safra N, Young A, Karmi N, Schaible RS, Ling GV. Mutations in the SLC2A9 gene cause hyperuricosuria and hyperuricemia in the dog. PLoS Genet. 2008:4(11):e1000246.

23. Fealey MJ, Li J, Todhunter RJE, Krotscheck U, Hayashi K, McConkey MJ, et al. Genetic mapping of principal components of canine pelvic morphology. Canine Genet Epidemiol. 2017;4:4.

24. Friedenberg SG, Lunn KF, Meurs KM. Evaluation of the genetic basis of primary hypoadrenocorticism in standard poodles using SNP array genotyping and whole-genome sequencing. Mamm Genome. 2017;28(1-2):56-65.

25. Pedersen NC, Liu H, Leonard A, Griffioen L. A search for genetic diversity among Italian greyhounds from continental Europe and the USA and the effect of inbreeding on susceptibility to autoimmune disease. Canine Genet Epidemiol. 2015:2:17.

26. Pedersen NC, Pooch AS, Liu H. A genetic assessment of the English bulldog. Canine Genet Epidemiol. 2016;3:6.

27. DG ON, Church DB, McGreevy PD, Thomson PC, Brodbelt DC. Prevalence of disorders recorded in dogs attending primary-care veterinary practices in England. PLoS One. 2014;9(3):e90501.

28. Oberbauer AM, Belanger JM, Bellumori T, Bannasch DL, Famula TR. Ten inherited disorders in purebred dogs by functional breed groupings. Canine Genet Epidemiol. 2015:2:9.

29. Bellumori TP, Famula TR, Bannasch DL, Belanger JM, Oberbauer AM. Prevalence of inherited disorders among mixed-breed and purebred dogs: 27,254 cases (1995-2010). J Am Vet Med Assoc. 2013;242(11):1549-55.

30. Greer KA, Canterberry SC, Murphy KE. Statistical analysis regarding the effects of height and weight on life span of the domestic dog. Res Vet Sci. 2007;82(2):208-14.

31. Egenvall A, Bonnett BN, Hedhammar A, Olson P. Mortality in over 350,000 insured Swedish dogs from 1995-2000: II. Breed-specific age and survival patterns and relative risk for causes of death. Acta Vet Scand. 2005;46(3):121-36.

32. Urfer SR, Kaeberlein M, Promislow DEL, Creevy KE. Lifespan of companion dogs seen in three independent primary care veterinary clinics in the United States. Canine Med Genet. 2020;7:7.

33. Urfer SR, Wang M, Yang M, Lund EM, Lefebvre SL. Risk factors associated with lifespan in pet dogs evaluated in primary care veterinary hospitals. J Am Anim Hosp Assoc. 2019:55(3):130-7.

34. O'Neill DG, Pegram C, Crocker P, Brodbelt DC, Church DB, Packer RMA Unravelling the health status of brachycephalic dogs in the UK using multivariable analysis. Sci Rep. 2020;10(1):17251.

35. Sutter NB, Bustamante CD, Chase K, Gray MM, Zhao K, Zhu L, et al. A single IGF1 allele is a major determinant of small size in dogs. Science. 2007;316(5821):112-5.

36. Jones P, Chase K, Martin A, Davern P, Ostrander EA, Lark KG. Single-nucleotide-polymorphism-based association mapping of dog stereotypes. Genetics. 2008:179(2):1033-44. 
37. Boyko AR, Boyko RH, Boyko CM, Parker HG, Castelhano M, Corey L, et al. Complex population structure in African village dogs and its implications for inferring dog domestication history. Proc Natl Acad Sci U S A. 2009;106(33):13903-8.

38. Parker HG, VonHoldt BM, Quignon P, Margulies EH, Shao S, Mosher DS, et al. An expressed fgf 4 retrogene is associated with breed-defining chondrodysplasia in domestic dogs. Science. 2009;325(5943):995-8

39. Bannasch D, Young A, Myers J, Truve K, Dickinson P, Gregg J, et al. Localization of canine brachycephaly using an across breed mapping approach. PLoS One. 2010;5(3):e9632.

40. Hayward JJ, Castelhano MG, Oliveira KC, Corey E, Balkman C, Baxter TL, et al. Complex disease and phenotype mapping in the domestic dog. Nat Commun. 2016;7:10460

41. Plassais J, Rimbault M, Williams FJ, Davis BW, Schoenebeck JJ, Ostrander EA. Analysis of large versus small dogs reveals three genes on the canine $\mathrm{X}$ chromosome associated with body weight, muscling and back fat thickness. PLoS Genet. 2017;13(3):e1006661.

42. Mansour TA, Lucot K, Konopelski SE, Dickinson PJ, Sturges BK, Vernau $\mathrm{KL}$, et al. Whole genome variant association across 100 dogs identifies a frame shift mutation in DISHEVELLED 2 which contributes to Robinowlike syndrome in bulldogs and related screw tail dog breeds. PLoS Genet. 2018;14(12):e1007850.

43. Plassais J, Kim J, Davis BW, Karyadi DM, Hogan AN, Harris AC, et al. Whole genome sequencing of canids reveals genomic regions under selection and variants influencing morphology. Nat Commun. 2019;10(1):1489.

44. Jansson M, Laikre L. Recent breeding history of dog breeds in Sweden: modest rates of inbreeding, extensive loss of genetic diversity and lack of correlation between inbreeding and health. J Anim Breed Genet. 2014;131(2):153-62.

45. Kumpulainen M, Anderson H, Svevar T, Kangasvuo I, Donner J, Pohjoismaki J. Founder representation and effective population size in old versus young breeds-genetic diversity of Finnish and Nordic Spitz. J Anim Breed Genet. 2017;134(5):422-33.

46. Silver L. Mouse genetics concepts and applications. Oxford: Oxford University Press; 1995.

47. Dreger DL, Davis BW, Cocco R, Sechi S, Di Cerbo A, Parker HG, et al. Commonalities in development of pure breeds and population isolates revealed in the genome of the Sardinian Fonni's dog. Genetics. 2016;204(2):737-55.

48. Sams AJ, Boyko AR. Fine-scale resolution of runs of Homozygosity reveal patterns of inbreeding and substantial overlap with recessive disease genotypes in domestic dogs. G3 (Bethesda). 2019;9(1):117-23.

49. Chu ET, Simpson MJ, Diehl K, Page RL, Sams AJ, Boyko AR. Inbreeding depression causes reduced fecundity in Golden retrievers. Mamm Genome. 2019;30(5-6):166-72.
50. Schrack J, Dolf G, Reichler IM, Schelling C. Factors influencing litter size and puppy losses in the Entlebucher Mountain dog. Theriogenology. 2017:95:163-70.

51. Bonnett BN, Egenvall A. Age patterns of disease and death in insured Swedish dogs, cats and horses. J Comp Pathol. 2010;142(Suppl 1):S33-8.

52. Bonnett BN, Egenvall A, Hedhammar A, Olson P. Mortality in over 350,000 insured Swedish dogs from 1995-2000: I. breed-, gender-, age- and cause-specific rates. Acta Vet Scand. 2005;46(3):105-20.

53. Lampi S, Donner J, Anderson H, Pohjoismäki J. Variation in breeding practices and geographic isolation drive subpopulation differentiation, contributing to the loss of genetic diversity within dog breed lineages. Canine Med Genet. 2020;7:5.

54. Meagher S, Penn DJ, Potts WK. Male-male competition magnifies inbreeding depression in wild house mice. Proc Natl Acad Sci U S A. 2000;97(7):3324-9.

55. Rudan I, Rudan D, Campbell H, Carothers A, Wright A, Smolej-Narancic $\mathrm{N}$, et al. Inbreeding and risk of late onset complex disease. J Med Genet. 2003:40(12):925-32.

56. Knowler SP, v/d Berg H, McFadyen A, La Ragione RM, Rusbridge C. Inheritance of Chiari-like malformation: can a mixed breeding reduce the risk of Syringomyelia? PLoS One. 2016;11(3):e0151280.

57. Stronen AV, Salmela E, Baldursdóttir BK, Berg P, Espelien IS, Järvi K, et al. Genetic rescue of an endangered domestic animal through outcrossing with closely related breeds: a case study of the Norwegian Lundehund. PLoS One. 2017;12(6):e0177429.

58. Windig JJ, Doekes HP. Limits to genetic rescue by outcross in pedigree dogs. J Anim Breed Genet. 2018;135(3):238-48.

59. Purcell $S$, Neale B, Todd-Brown K, Thomas L, Ferreira MA, Bender D, et al. PLINK: a tool set for whole-genome association and population-based linkage analyses. Am J Hum Genet. 2007;81 (3):559-75.

60. Anderson R. Modern methods for robust regression. Sage Publications. 2008.

61. Venables WNRB. Modern applied statistics with S-PLUS. Berlin: Springer Science \& Business Media; 2013

62. R Core Team. R: A language and environment for statistical computing. Vienna: R Foundation for Statistical Computing; 2013. http://www.R-proje ct.org/.

63. Maechler M. sfsmisc: Utilities from 'Seminar fuer Statistik'ETH Zurich. 2020.

\section{Publisher's Note}

Springer Nature remains neutral with regard to jurisdictional claims in published maps and institutional affiliations.
Ready to submit your research? Choose BMC and benefit from:

- fast, convenient online submission

- thorough peer review by experienced researchers in your field

- rapid publication on acceptance

- support for research data, including large and complex data types

- gold Open Access which fosters wider collaboration and increased citations

- maximum visibility for your research: over $100 \mathrm{M}$ website views per year

At BMC, research is always in progress.

Learn more biomedcentral.com/submissions 